\title{
Why Zlatan Ibrahimović is Bigger Than Manchester United: Investigating Digital Traces in Co-branding Processes on Social Media Platforms
}

\author{
Vasili Mankevich \\ Department of Informatics, Umeå \\ University, Sweden \\ vasili.mankevich@umu.se
}

\author{
Jonny Holmström \\ Department of Informatics, Umeå \\ University, Sweden \\ jonny.holmstrom@umu.se
}

\author{
Ian P. McCarthy \\ Beedie School of Business, Simon \\ Fraser University, Canada \\ imccarth@sfu.ca
}

\begin{abstract}
The purpose of this study is to examine the cobranding activity on social media platforms, particularly in regard to company-employee relationship. We conducted a case study of co-branding on Instagram involving the soccer club Manchester United and the soccer player Zlatan Ibrahimović. We performed sentiment and emotional tone analysis, assessed intersection of the audience and illustrated non-verbal communication used by social media users. We demonstrated how the soccer club failed to capitalize on co-branding activity as measured through consolidating the audience, generating consistent emotional response, and creating a coherent message. This paper contributes to social media management research by illustrating the difficulties associated with co-branding between personal and corporate brands as well asynchronous communication. Further, our use of digital traces and computational analysis illustrates how access to social media can illuminate research activities and provide insight about online communication.
\end{abstract}

\section{Introduction}

In today's world of social media platforms, firms are increasingly engaging in co-branding efforts partnering with established brands to leverage new value. As such, co-branding refers to the combination of two brands to create a single, new product $[1,2]$, an alternative for brand extensions with the purpose of achieving growth through new product development [3]. For example, GoPro (a portable camera company) and Red Bull (an energy drink company) co-brand their products as lifestyle offerings for adventurous athletes [4]. Co-branding can be facilitated by social media platforms - computer-mediated tools for creation and sharing of information within various communities [5]. The emergent popularity of these platforms sets fundamentally distinct demands on how companies communicate and collaborate [6, 7]. Social media platforms also enable companies to develop compelling stories that allow to enhance consumer connections to their brands [8].

The branding opportunities for sport clubs like Manchester United have already been extended through recent developments in digital technologies [9]. Specifically, the rise of social media platforms in the sports context has enabled professional sports teams to enhance the frequency and intensity of their interactions with their audience [10]. The provision of mobile services - such as smartphone apps that provide player statistics and betting functionality - has become a crucial part of formulating sport marketing strategies and gave several benefits for professional sports teams [11]. Even though individual athletes are relevant assets and investments, professional sports teams need to concentrate their efforts on managing the team's brand [12] and align these efforts with the brands of the individual athletes.

However, despite the potential benefits for firms to capitalize on co-branding with high-profile athletes and celebrities, empirical studies examining co-branding between organizations and individual brands remain surprisingly scarce [13]. While individuals can develop and promote their own personal brands [14], one must consider the rise (and sometimes fall) of the brands of individuals such as Oprah Winfrey, Tiger Woods and Lance Armstrong, and how there are risks for companies seeking to sponsor and co-brand with such individuals. Leveraging long-term value from a brand requires a vision driving the brand activities [15], which is particularly important in relation to branding efforts on social media platforms. One of the gaps in current research is the lack of studies addressing co-branding on social media platforms explicitly - a serious shortcoming. Moreover, we were unable to identify any studies in which co-branding unfolding on a social media platform was between an employee and a firm.

The purpose of this paper is to address the following research question: what are the challenges and opportunities associated with co-branding between corporate and individual brands on social media platforms? To do this, we explore the case of cobranding between two strong brands: the soccer player Zlatan Ibrahimović and the British soccer team 
Manchester United. In this context, we examine how a successful co-branding initiative is one that provides a strong value exchange for both the employee (in our case an individual athlete) and the employer (e.g. the sporting club) involved in the co-branding arrangement. The case demonstrates that while the strategic intent behind a brand alliance is to combine a firm's brand identity with that of its partner to create a new, stronger competitive position in the market [16] a poor execution of synergies on social media platforms can lead to failure to deliver on the co-branding process.

\section{Related research}

Prior studies of brand partnerships in marketing have had an emphasis on the role and importance of participating brands from a managerial and consumer perspective [e.g. 17]. Many definitions of co-branding exist at the inter-organizational, promotional, and product levels. Keller, Apéria and Georgson [18], state that co-branding occurs when two or more brands are combined into a joint product or are marketed together in some form. According to Helmig, Huber, and Leeflang [19], co-branding represented "a long-term brand alliance strategy in which one product is branded and identified simultaneously by two brands". Park, Jun, and Shocker [20] defined co-branding as the pairing of two or more branded products (constituent brands) to form a separate and unique product (composite brand), and Blackett and Russell [21] viewed co-branding as the mutual enhancement of two brands through close association of a product or service.

Even though differences in the definition of co-branding occur, most authors agree that co-branding involves combining two partners' brands to create a single offering. As such, two dominant perspectives can be identified in extant research: the managerial perspective and the customer perspective. The managerial perspective includes attention to issues such as why brands form alliances, and the consequences of brand alliance decisions and desired brand partner characteristics. The consumer perspective includes attention to factors that influence consumers' perception, pre/post evaluation of constituent brands and consumers' learning in a brand alliance [e.g. 22, 23, 24].

In relation to the sporting context, extant research has been focusing extensively on the sponsorship relationship between athletic teams and large companies. Specifically, sponsorship has been identified as a driver for brand strategy, particularly through efficient co-branding [25]. Such relationships might be used to redefine company's brand identity and build brand equity [26]. Co-branding in sporting contexts has also been studied as a relationship between teams and large associations and even cities, e.g. Olympic games [27] or hosting cities [28]. Studies have investigated how the co-branding efforts are conducted in a larger institutional context and require wider recognition of the factors at play, as well as better understanding of the underlying phenomenon.

Co-branding refers to any pairing of brands in a collaborative marketing effort [29], including advertisements, services, promotions, public linkages or distribution outlets $[30,31]$. The purpose of linking two brands involves both an image transfer and the integration of a new physical attribute into an existing brand [32]. On the basis of this definition, scholars assign various interchangeable labels to co-branding: composite brand extension [20], co-marketing alliance [33], ingredient branding, multi-branding [34], joint branding [35] and brand alliance [23].

Traditionally, normative approaches to co-branding have seen corporate brands as created and managed by senior management (e.g. a managerial perspective). However, more recently, consumer perspective approaches have argued for corporate brands as vehicles of meaning that emerge from social interaction between the company and its customers (e.g. a consumer perspective). To date, these two perspectives have been positioned as alternative approaches to co-branding. We argue that further progress in co-branding research should be driven by an understanding of the emergence of social media platforms and how this emergence changes the nature of co-branding.

Indeed, the emergence of social media platforms has enabled a shift in focus from the managerial and customer to a technology perspective, with a specific attention to the enabling properties of social media platforms. As such, we understand social media platforms as a social interaction-enhancing technology that can be deployed by professionals to generate content and develop networks [36]. Aligning this view with the co, branding literature, we arrive at the following landscape:

Table 1: Perspectives on co-branding

\begin{tabular}{|l|l|l|}
\hline $\begin{array}{l}\text { Perspective } \\
\text { on co- } \\
\text { branding }\end{array}$ & Focal concern & Key References \\
\hline $\begin{array}{l}\text { Consumer } \\
\text { perspective }\end{array}$ & $\begin{array}{l}\text { How consumers } \\
\text { relate to co-branding } \\
\text { initiatives }\end{array}$ & $\begin{array}{l}\text { Venkatesh and } \\
\text { Mahajan [24], } \\
\text { Simonin and Ruth } \\
{[23], \text { Rao, et al. }} \\
{[22]}\end{array}$ \\
\hline $\begin{array}{l}\text { Managerial } \\
\text { perspective }\end{array}$ & $\begin{array}{l}\text { How co-branding } \\
\text { initiatives can be } \\
\text { leveraged to benefit } \\
\text { the partners }\end{array}$ & $\begin{array}{l}\text { Leuthesser, et al. } \\
{[37], \text { Blackett and }} \\
\text { Russell [21], } \\
\text { Washburn, et al. } \\
{[38]}\end{array}$ \\
\hline
\end{tabular}




\begin{tabular}{|l|l|l|}
\hline $\begin{array}{l}\text { Technology } \\
\text { perspective }\end{array}$ & $\begin{array}{l}\text { How technology can } \\
\text { be used in co- } \\
\text { branding initiatives }\end{array}$ & $\begin{array}{l}\text { Keller and } \\
\text { Lehmann [15] }\end{array}$ \\
\hline
\end{tabular}

The co-branding literature may be characterized as a domain that is currently very much practitioner-led and where academic research has been slow to follow, although high levels of academic interest in the topic are now beginning to materialize. The consumer perspective and the management perspective are pervasive in extant research, while the technology perspective is largely missing. Given the pervasive role of social media platforms today, this is unfortunate. However, despite social media's ability to influence key aspects of branding and consumer behavior [e.g. 39], little research has been carried out into its dynamics. As such, the focus of this research is on co-branding on social media platforms as an impetus for brand partnerships, with a specific emphasis on the ways in which a firm's brand identity can be combined with that of its partner to create a stronger competitive position in the market, and how asynchronous activities may lead to failure to deliver on the co-branding process. As such, we see an opportunity for future studies to capture cobranding between a firm and its employees. This creates a number of challenges that need to be addressed. In particular we are interested in how the audience transition between the brands, what emotional response does it generate, and how coherent is the strategic message in this form of communication? To address these questions, we study the case of co-branding between two strong brands: the soccer player Zlatan Ibrahimović and the British soccer team Manchester United.

\section{Research Methodology}

The emergence of social media platforms provides researchers with new opportunities for data collection and subsequent theorizing. The digital traces found on platforms such as Instagram and Facebook provide rich accounts of user activity and interactions between stakeholders such as athletes and fans [e.g. 40]. As such, the unprecedented wealth of digital traces opens up possibilities for research that complements traditional qualitative methods by "harnessing the data contained in online archives and using it to operationalize concepts of deep theoretical interest" [41].

We approached the study of co-branding between two entities as a case study [42], following the extreme sample selection technique proposed by Gerring [43]: one that provides a revelatory account suitable for theory building [44] and exploration of the distributed innovation agency on the depth [45] rather than breadth.
In the study, we explored how two entities - the soccer player Zlatan Ibrahimović and the soccer club Manchester United - engaged in co-branding through one episode: when the club purchased the player and he became an employee of the club. For the analysis, we collected commentaries from Instagram posts related to the player transfer. During the first month after transfer announcement (June 30th - July 30th 2016) we identified nine posts suitable for the analysis: one by Ibrahimović and eight by Manchester United, that contained a total of 64'555 comments (at the time of the data collection).

In order to collect data from social media accounts we have used browser automation through Selenium [46] web browsing technique, making use of the Easily Harvest Web Pages tools [47] for capturing data from the pages. This approach allowed us to collect all available information related to the investigated cobranding episode. Next, we assessed the audience of the both accounts: compared the user id and found the intersection between the two (e.g. commentators that posted in both accounts). We visualized data using a Venn diagram [48].

Further, we performed sentiment analysis on the data - linguistic analysis which allows to assess writer's attitude on the spectrum from positive to negative - one of the most fundamental tasks in text analysis [49]. We used the "AFINN Word Database" [50] and the "Syuzhet" toolset [51]. The sentiment analysis was performed by name matching with lexicon lists, where each word was scored for valence based on the previous qualitative assessment of the vocabulary. For example, "GOOD luck" comment had sentiment score of 6 , while comment "Terrible choice MU!" had a sentiment score -3. AFINN lexicon is specifically constructed for microblogs, includes internet slang and obscene language, hence increasing accuracy in cases of short sentenced communication (such as Instagram comments). The sequence of comments was then divided in 100 equal parts and plotted to represent mean sentiment scores corresponding to each part (percent) of the narrative.

In addition, we conducted an analysis to assess emotional tone of the comments. As such, we made use of the lexicon that describes which emotions are evoked by common phrases and words [52]. This exercise allowed us to assess the relative emotional score of the comments in each of the social media accounts. The emotional tones included following categories: anger, anticipation, disgust, fear, joy, sadness, surprise, trust, negative and positive sentiment. Moreover, Internet users increasingly use non-verbal graphic modes of communication, such as emoticons and emojis [53]. Emojis are ideograms that are used to express common emotions such as a smile, sadness, and laughter. To 
account for this type of communication, we also conducted analysis of the emoji use. We processed all comments for matching emoticon codes lexicon [54].

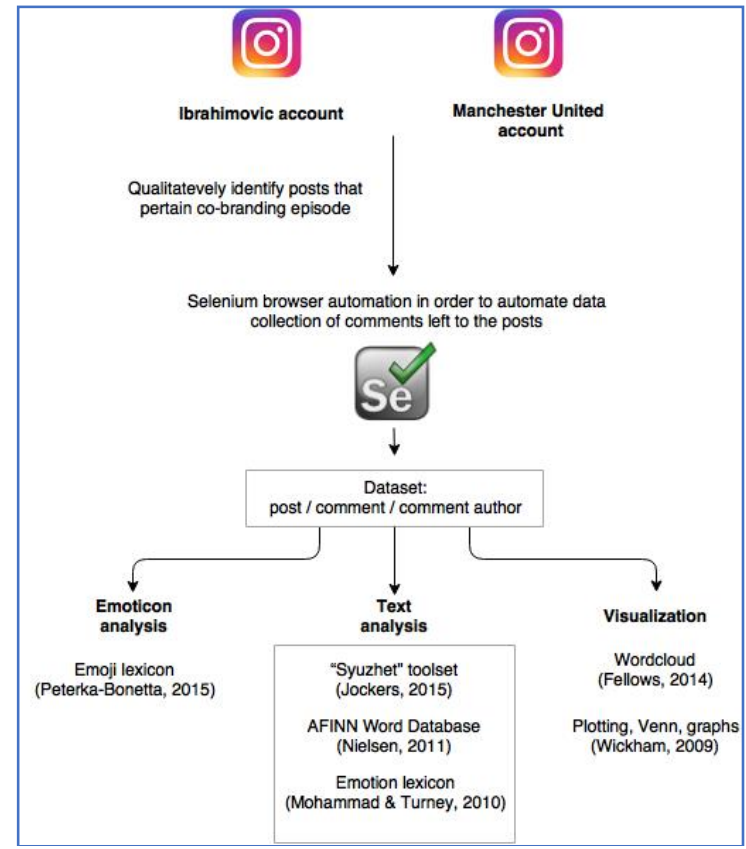

Figure 1. Research procedure

The results of computational analysis often present a challenge for visualization and presentation $[55,56]$. Quantitative results were visualized into graphs with the aid of ggplot2 [57]. We also visualized the top 100 most common words in the dataset into a word cloud [58], with the aim of creating a crude representation of the most common themes in the dataset. See figure 1 for the visualization of the research procedure.

\section{Results}

Manchester United is the most decorated club in England and at $\$ 3.69$ billion is the highest valued soccer club in the world [59]. Zlatan Ibrahimovic is the third most decorated soccer player in the world (32 trophies). He started his professional career in Sweden in 1999 and since then played for high-profile soccer clubs: Juventus, Milan, Barcelona, Paris Saint-Germain. He made more than 100 appearances for the Swedish national team representing Sweden at FIFA World cups and UEFA European championships. During his previous transfer from Milan to PSG Ibrahimović was acquired for \$20.1 million [60]. After the investigate transfer to Manchester United, Ibrahimović's salary at the club stood out and was described as "astronomical" [61].

In our study, we assessed the development of the brands in the context of asynchronous communication i.e. chronologically and thematically incompatible information flow. We collected the data pertaining to the transition of Zlatan Ibrahimović to the Manchester United in June of 2016. To do this, we used two social media profiles: the personal and official account of Zlatan Ibrahimović and the official account of Manchester United on Instagram. Ibrahimović delivered the announcement that he was joining Manchester United first, through a single communication thrust on Instagram. This is very uncommon since the soccer club management usually delivers information about player transfers before the individual player makes an announcement. Media regarded such announcement as "unorthodox", a "bombshell", and "one of the worst kept secrets in football" [61]. Manchester United quickly followed with a series of seven detailed announcements on the same social media platform. See in table 2 the details of each post: the number of likes, comments, and unique commentators per each individual post.

Table 2. Instagram posts announcing Manchester United's signing of Zlatan Ibrahimović

\begin{tabular}{|c|c|c|c|c|}
\hline Post & $\begin{array}{l}\text { Likes (in } \\
\text { thousands }\end{array}$ & $\begin{array}{l}\text { Comme } \\
\text { nts }\end{array}$ & $\begin{array}{l}\text { Unique } \\
\text { authors }\end{array}$ & $\begin{array}{l}\text { Date } \\
(2016)\end{array}$ \\
\hline Zlatan & 1'100 & $48^{\prime} 258$ & $42^{\prime} 698$ & June 30 \\
\hline MU1 & 594 & $2^{\prime} 574$ & $2 ' 409$ & July 1 \\
\hline MU2 & 531 & 4’394 & 4'111 & July 1 \\
\hline MU3 & 347 & $1 ’ 053$ & 967 & July 1 \\
\hline MU4 & 711 & 958 & 885 & July 1 \\
\hline MU5 & 712 & 1’086 & $1 ’ 035$ & July 1 \\
\hline MU6 & 493 & 2'653 & $2 ’ 459$ & July 1 \\
\hline MU7 & 1'100 & $2^{\prime} 136$ & 1'669 & July 2 \\
\hline MU8 & 378 & 1'443 & $1 ’ 316$ & July 2 \\
\hline $\begin{array}{l}\text { MU } \\
\text { Total }\end{array}$ & 4’900 & $16 ’ 297$ & $14^{\prime} 310$ & \\
\hline
\end{tabular}

\subsection{Audience}

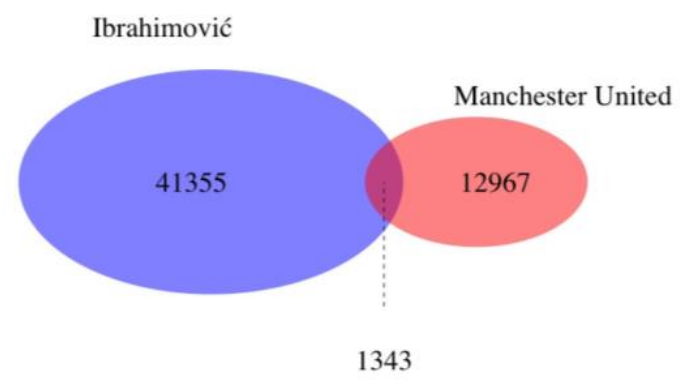

Figure 2. Audience intersection

One of the co-branding goals is to expose the audience of one brand to the audience of the other brand. We conducted an analysis of the audience in the posts by Manchester United and Ibrahimović. First, most of the authors commenting to Manchester United and Ibrahimović's posts left only one message ( $88 \%$ and $87 \%$ respectively). Our analysis showed that only a small number of users attended to both accounts, namely 
1,343 or $2 \%$ of the total number of commentators). In figure 2 we present a Venn diagram of the number of unique commentators that participated in the discussions (blue color represents commentators in Ibrahimović post, red color Manchester United posts) and their intersection (commentators that participated in discussions in both accounts).

\subsection{Sentiment and emotional tone}

We also explored the sentiment of the posts and discovered a high variance in relation to the time narrative of the announcement (see figures 3). By narrative we mean the sequence of successive comments, starting from the first comment, and ending with the last posted comment on the time when the data collection took place. This approach was chosen due to the data limitation: no access to the timestamp information of the comments. That being said, we consider the narrative approach appropriate since it offers us to see the progression of the sentiment development since the post publication to the data collection episode.

Figure 3 shows sentiment means throughout the narrative: all messages are divided in 100 successive periods and sentiment score means are calculated for them. While the overall sentiment score was higher in the Ibrahimović's account, we also see splashes of negative sentiment among the commentators. There is a very distinct increase of the sentiment means in the Manchester United account comments towards the second half of the narrative, which can be attributed to the effect of repetitive communication episodes with a several separate posts.

Taking it one step further, we assessed the emotional tone on the detailed 8-category scale. More granular analysis of the comments' sentiment showed assessment of comments beyond positive-negative dichotomy, giving a more accurate representation of the messages' sentiment. The analysis showed, once again, significantly higher emotional tone sentiment score for the Ibrahimović's account, even in relative terms. See appendix for Welch two sample test. The relative score was calculated by dividing each score by a total number of comments (e.g. Ibrahimović's anger score 1,946 divided by 48,258). See figure 4 for a detailed comparison.

Our analysis of the emoji - a common graphical way of expressing emotions on social media - is presented in figure 5. We observed an overlap in the use of particular emoji types, the figure represents a relative count (emoji per comment) of the top 11 most commonly used graphic symbols. That being said, we noted that the relative count of such non-verbal communication is higher in the comments to Ibrahimović's account. For example: proportionally, heart symbol was used in almost $11 \%$ of comments to players post, while only in $6.6 \%$ of comments to the posts of Manchester United. See figure 5 for emoji use.
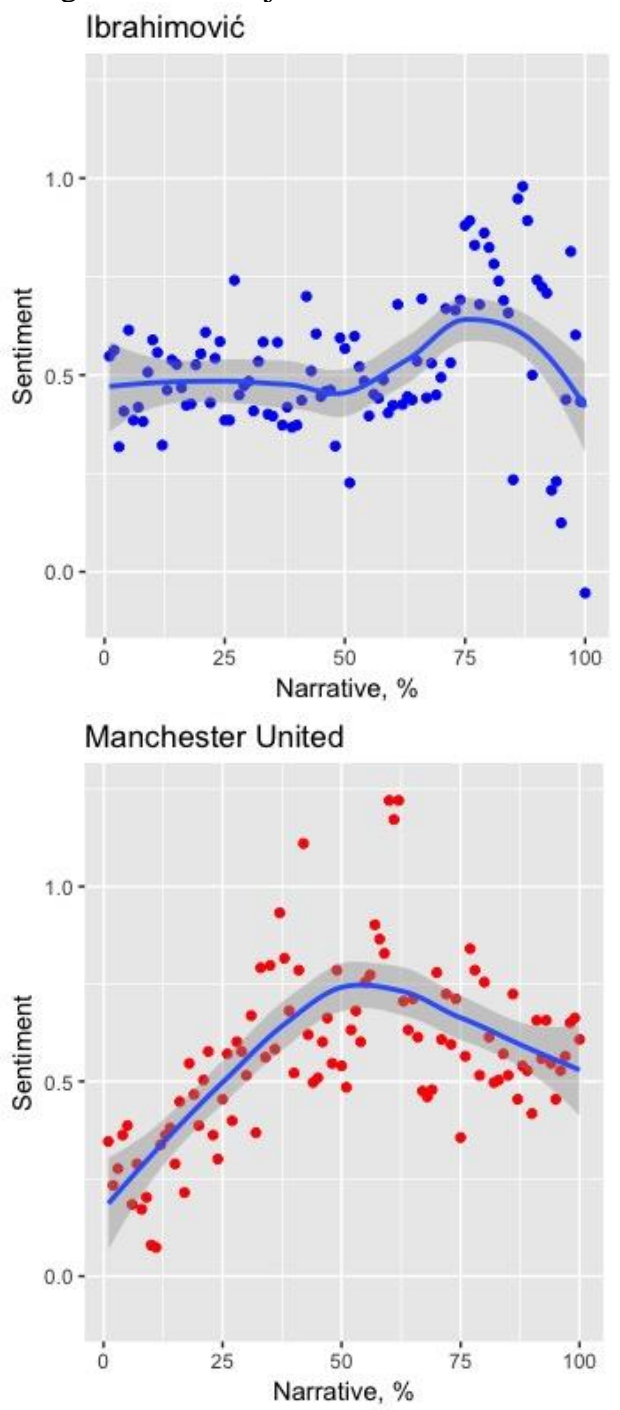

Figure 3. Sentiment means throughout the narrative

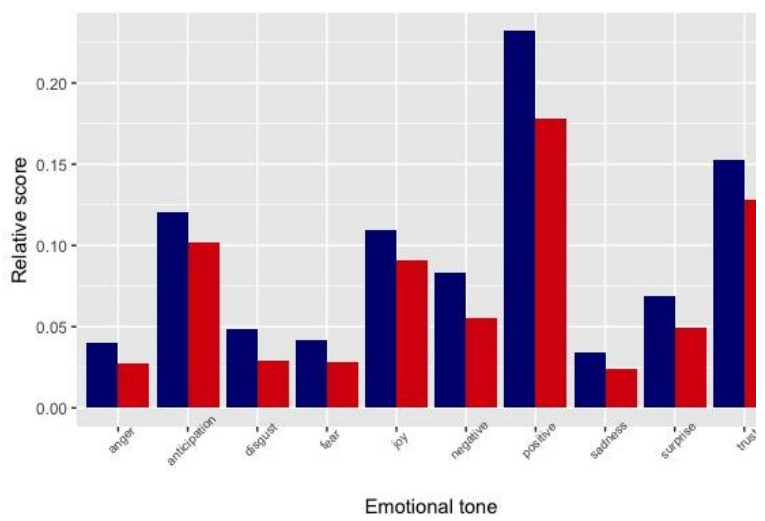

Figure 4. Emotional tone 


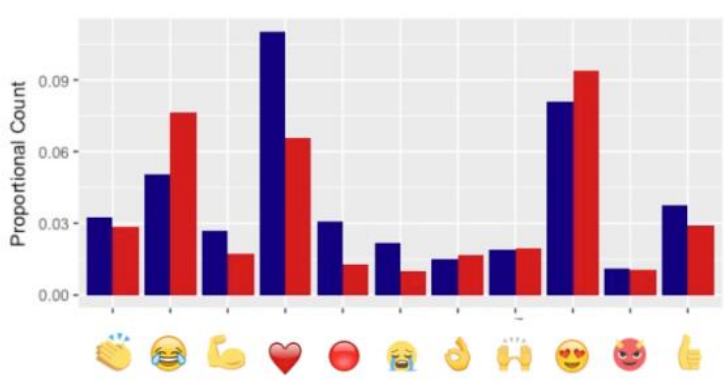

Figure 5. Emoji use, proportional count

\subsection{Communication coherence}

The established tradition of short length of commentaries (in our sample median is 3 words per comment) presented us with significant challenges for topic analysis. Still, to give the reader a general overview of the prevalent conversations we present word clouds for both accounts (see figure 6). After removal of the stop words and words related to the player and the club themselves, we see somewhat different pictures. Manchester United followers are concerned with the jersey number and Zlatan's potential relationship with other players (in particular Rooney), while Ibrahimović's followers are very expressive about their feelings, often using slang and profanity (removed from visualization).

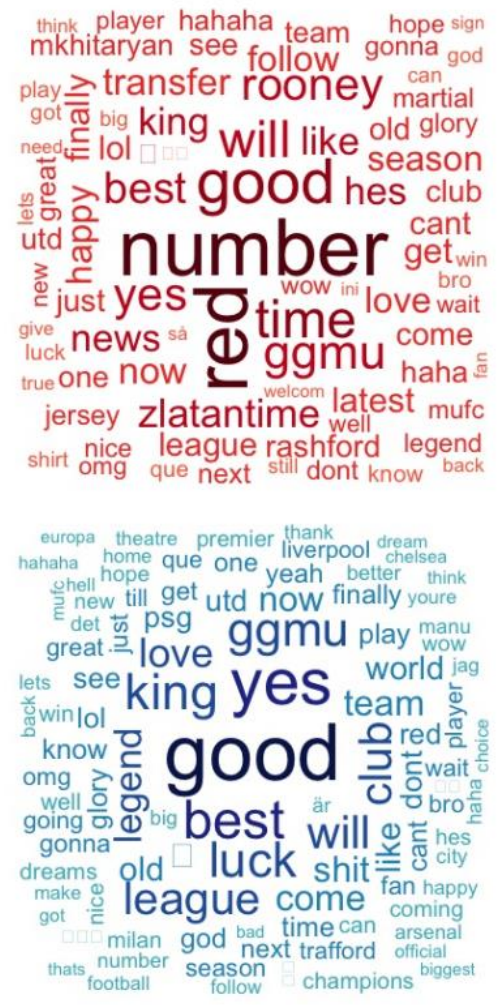

Figure 6. Word cloud comparison in two accounts; Manchester United vs. Zlatan

As the analysis demonstrated, co-branding on social media is a complex phenomenon that can produce unexpected outcomes. The analysis focused on the Zlatan Ibrahimović-Manchester United case to understand how co-branding may develop from a simple transaction at one end of a continuum into a more strategic and complex corporate co-brand at the other end of the continuum. From this perspective, our findings demonstrate how the two brands struggled in creating a stronger competitive position in the market. Specifically, we demonstrate how the co-branding activity failed in (1) consolidating the audience, (2) generating consistent emotional response, and (3) creating a coherent message.

\section{Discussion}

This research was focused on co-branding on social media platforms as an impetus for brand partnerships. More specifically, we studied the case of co-branding between two strong brands: the soccer player Zlatan Ibrahimović and the British soccer team Manchester United. In so doing we focused on the ways in which a sporting club's (employer) brand identity can be combined with that of its athlete (employee) to create a stronger competitive position in the market. We found that asynchronous communication as well as disparity in social media profiles (individual vs corporate) lead to failure to deliver on the co-branding process. This finding underscored how branding via social media platforms has changed the nature of co-branding, particularly in relation to firm-employee co-branding. In so doing we showed that while the strategic intent behind a brand alliance is to combine a firm's brand identity with that of its partner to create a new, stronger competitive position in the market, asynchronous activities and new format of communication on social media platforms may lead to unfavorable outcomes.

Co-branding efforts and the associated links between brands can enhance or deter customer perceptions of a product [1] hence the importance of understanding how these links are established and how they evolve over time. In our analysis, we investigated the co-branding between strong brands on social media platforms, the type of the emotional response they gather, and the contrasts between audience expressions to the co-branding activities. Building on digital trace data and computational analysis, we showed how results of the co-branding activities differ depending on initial conditions and brand profiles. To elaborate, we introduce three themes of key importance in cobranding activities on social media platforms: timing \& coherence, personalization, and adaptation. These three 
themes were identified because of empirical analysis of the failure to consolidate the audience, capitalize on brands' strengths, and create a coherent message (see previous section). We will discuss these notions in detail in what follows.

\subsection{Timing and Coherence}

Co-branding requires coordinated effort in communication flow, as well as timing in the execution. Brands capitalize on synergetic effects between their audiences, and as illustrated by the investigated case, the timing seemed to play a formative role on how the gains from the co-branding episode were distributed. In such cases, stronger brands typically capture consistent value, while weaker brands resort to other tactics (like recurrent communication thrusts) in order to capture some of the co-branding value. While the necessity to coordinate communication strategies is somewhat commonsensical, the case shows how even high-profile brands fail to thematically align their co-branding efforts.

The results of the case demonstrated how asynchronous communication fails to create a thematically coherent message. Arguably, the coherence (logical consistency, part of the whole) may not be the goal of the co-branding effort. It makes sense to adjust the communication contents in a way that would resonate with the different audiences. That being said, we argue that such incoherence of communication efforts (and the sentiments it evokes) creates challenges for the audience transition. In our case, only $2 \%$ of the participating audience (social media commentators) transposed in-between the accounts of Ibrahimović and Manchester United. Basic topic analysis also showed significant differences in thematic content of the users' comments. Failure to interchange audiences between two brands signals of inability to transfer image and attributes - one of the objectives of co-branding [32].

\subsection{Personalization}

Our study showed how brands differ in the extent of the emotional response they invoke from the audience. Personality driven brands seem to outperform organizational brands in the instance of co-branding activity on social media platforms. When communication is reduced to a series of images with short descriptions, it does not seem to be well suited for the expression of the complexities of the organizational identities, which can involve competing values $[62,63]$ and diverse activities. Social media platforms initially were designed for the individual use [64] and seem to favor personality driven brands. A platform such as Instagram allows their users to share memories and experiences (reinforcing the social media persona), but do little to leverage strengths of an organization in brand building.

The challenges in building the organizational brand in the digital age have been explored before [e.g. 65]. The way we learn about companies have changed dramatically: from strategic marketing efforts controlled by the company to the cornucopia of sources such as independent reviewers and customer blogs. Our study showed how the problem aggravates when an organizational brand interacts with a strong personalitybased brand online. As such, our findings illustrated how Ibrahimović invoked a much higher level of emotional response from the audience compared to Manchester United. Both in absolute and relative numbers, Ibrahimović's post gathered higher levels of sentiment and triggered much higher levels of emotions.

It is currently not clear how organizations can tackle challenges of branding through social media. Possible solution can be to approach organizational brand building through a composite of personalities online, building on individual brands that are separated but logically intact.

\subsection{Adaptation}

Previous research has poignantly described cobranding activities as a "marriage" [21], i.e. the relationship that involves careful selection, constant negotiation, and tactical adjustment. If such cooperation is absent - as illustrated in this study - the co-branding activity may fail to deliver value to the participating brands. Even worse, co-branding activity can result in damaged reputation and other negative outcomes [66]. In order to prevent such failure and maximize created value we suggest three adaptation activities to be performed by the brands. These activities especially relevant while embarking on the co-branding process at the social media platform such as Instagram.

First, we suggest a careful planning and coordination of the co-branding activities. Our case illustrated how even high-profile brands fail to coordinate, which leads to the signing of Ibrahimović becoming a "bombshell" and "one of the worst kept secrets in football" [61]. Coordination should be explicit: the speed and reach of information on social media is unprecedented while often lacking safeguarding mechanisms (e.g. editors) that are used in traditional marketing campaigns. This means a more careful approach to communication should be practiced.

Second, we suggest that co-branding activities on social media should build upon brands' audiences and employ better tactics in integrating them. The affordances of the platform allow cross-referencing and tagging, which should facilitate transposition of the audiences between the two brands. 
Lastly, we recommend an adaptive approach, since the interaction between organizational and personalitydriven brands is complicated. We suggest for organizations to adapt the stylistic and thematic style (usually more expressive and coherent) of the personality-driven brand in the co-branding activity. It is somewhat a counterintuitive notion, but since social media is de facto dominated by personality-driven brands (measured by followers, likes, and gathered sentiment), one can infer this approach to be preferential.

\section{Limitations and Future Research}

While computational natural language processing is a promising methodology for social scientists, it has a number of limitations [67]. Most significantly, the precision of the text analysis is often lower than one of the qualitative approaches, newest techniques in sentiment analysis at best approaching $87 \%$ accuracy [68], AFINN lexicon optimized for social media scoring at 56\% [50]. Computational analysis such as used in our study is also blind to the conversations in the data - how users interacted between each other on topics remote from the original post. Finally, while lexicons used in the study are at the forefront of the computational language processing, they still have limitations when it comes colloquialisms, specialized vocabulary and foreign languages. Bearing all these limitations in mind, we believe that the use of computational techniques provides a macro analysis of social phenomena online, something that was not possible before. Continuous improvement of these techniques should improve richness and accuracy of empirical studies such as ours.

Future research should concern with particular properties of social media platforms [5] and how they affect the ability of companies to capitalize on cobranding activities. Considering the functional areas of social media [14] future research should work in the direction of developing propositions that would guide co-branding between efforts of firms and individuals, capitalizing on such interactions and facilitating organizational storytelling.

\section{Conclusions}

We conclude by noting that the changing digital environment has potentially serious consequences for how branding activities are practiced and for the marketing function in general and sports marketing in particular. Our research findings contribute with a current perspective to ongoing debates concerning the evolving and increasingly troubled nature of marketing's role within the firm. Branding and co- branding activities, particularly in the context of firmemployee co-branding, requires a sensibility towards the dynamics of co-branding processes and the role that social media platform plays in such processes. While the emergence of social media platforms has enabled a shift in focus from the managerial and customer to a technology perspective, with a specific attention to the enabling properties of social media platforms, the marketing function in today's firms have not been adaptive to this shift. Our case demonstrates clearly that not only are Manchester United unable to reap cobranding benefits from partnering with Ibrahimović they are also unable to be sensitive towards what the opportunities and challenges in such co-branding processes are. As such, the recent proliferation in data analytics bring huge opportunities for co-branding processes in relation to market insight and the identification of target markets, as well as providing broader insights which can inform marketing strategy.

\section{References}

[1] R. Abratt and P. Motlana, "Managing co-branding strategies: Global brands into local markets," Business Horizons, vol. 45, no. 5, pp. 43-50, 2002/09/01 2002.

[2] P. Kumar, "The Impact of Cobranding on Customer Evaluation of Brand Counterextensions," Journal of Marketing, vol. 69, no. 3, pp. 1-18, 2005.

[3] K. L. Keller, 3rd., Ed. Strategic Brand Management: Building, Measuring and Managing Brand Equity. Upper Saddle River, NJ: Prentice Hall, 2008.

[4] R. E. Kunz, F. Elsässer, and J. Santomier, "Sportrelated branded entertainment: the Red Bull phenomenon," Sport, Business and Management: An International Journal, vol. 6 , no. 5, pp. 520-541, 2016.

[5] P. M. Leonardi and E. Vaast, "Social Media and Their Affordances for Organizing: A Review and Agenda for Research," Academy of Management Annals, vol. 11, no. 1, pp. 150-188, 2017.

[6] S. Aral, C. Dellarocas, and D. Godes, "Introduction to the Special Issue-Social Media and Business Transformation: A Framework for Research," Information Systems Research, vol. 24, no. 1, pp. 3-13, 2013/03/01 2013.

[7] F. Tan, J. Hedman, and X. Xiao, "Beyond 'Moneyball'to Analytics Leadership in Sports: An Ecological Analysis of Fc Bayern Munich's Digital Transformation," 2017.

[8] S. Singh and S. Sonnenburg, "Brand Performances in Social Media," Journal of Interactive Marketing, vol. 26, no. 4, pp. 189-197, 2012/11/01/ 2012.

[9] J. S. Hill and J. Vincent, "Globalisation and sports branding: the case of Manchester United," International Journal of Sports Marketing and Sponsorship, vol. 7, no. 3, pp. 61-78, 2006.

[10] P. Parganas, C. Anagnostopoulos, and S. Chadwick, "Effects of social media interactions on brand associations: A comparative study of soccer fan clubs," International Journal 
of Sports Marketing and Sponsorship, vol. 18, no. 2, pp. 149165, 2017.

[11] J.-P. Ha, S. J. Kang, and Y. Kim, "Sport fans in a "smart sport" (SS) age: drivers of smartphone use for sport consumption," International Journal of Sports Marketing and Sponsorship, vol. 18, no. 3, pp. 281-297, 2017/08/07 2017.

[12] V. Baena, "Online and mobile marketing strategies as drivers of brand love in sports teams: Findings from Real Madrid," International Journal of Sports Marketing and Sponsorship, vol. 17, no. 3, pp. 202-218, 2016.

[13] L. C. Ueltschy and M. Laroche, "Co-Branding Internationally: Everyone Wins?," Journal of Applied Business Research, vol. 20, no. 3, 2011.

[14] J. H. Kietzmann, K. Hermkens, I. P. McCarthy, and B. S. Silvestre, "Social media? Get serious! Understanding the functional building blocks of social media," Business Horizons, vol. 54, no. 3, pp. 241-251, 5// 2011.

[15] K. L. Keller and D. R. Lehmann, "Assessing longterm brand potential," Journal of Brand Management, vol. 17, no. 1, pp. 6-17, 2009// 2009.

[16] J. Hagedoorn, "Understanding the rationale of strategic technology partnering: Nterorganizational modes of cooperation and sectoral differences," Strategic Management Journal, vol. 14, no. 5, pp. 371-385, 1993.

[17] K. E. Voss and P. Tansuhaj, "A Consumer Perspective on Foreign Market Entry," Journal of International Consumer Marketing, vol. 11, no. 2, pp. 39-58, 1999/09/24 1999.

[18] K. L. Keller, T. Apéria, and M. Georgson, Strategic brand management: A European perspective. Harlow: Pearson, 2008.

[19] B. Helmig, J. A. Huber, and P. S. Leeflang, "Cobranding: The state of the art," University of Fribourg Marketing2007.

[20] C. W. Park, S. Y. Jun, and A. D. Shocker, "Composite Branding Alliances: An Investigation of Extension and Feedback Effects," Journal of Marketing Research, vol. 33, no. 4, pp. 453-466, 1996.

[21] T. Blackett and N. Russell, "Co-branding - the science of alliance," Journal of Brand Management, journal article vol. 7, no. 3, pp. 161-170, 2000.

[22] A. R. Rao, L. Qu, and R. W. Ruekert, "Signaling Unobservable Product Quality through a Brand Ally," Journal of Marketing Research, vol. 36, no. 2, pp. 258-268, 1999.

[23] B. L. Simonin and J. A. Ruth, "Is a Company Known by the Company It Keeps? Assessing the Spillover Effects of Brand Alliances on Consumer Brand Attitudes," Journal of Marketing Research, vol. 35, no. 1, pp. 30-42, 1998.

[24] R. Venkatesh and V. Mahajan, "Products with Branded Components: An Approach for Premium Pricing and Partner Selection," Marketing Science, vol. 16, no. 2, pp. 146165, 1997/05/01 1997.

[25] H. Frederick and S. Patil, "The dynamics of brand equity, co-branding and sponsorship in professional sports," International Journal of Sport Management and Marketing, vol. 7, no. 1-2, pp. 44-57, 2010.

[26] J. Motion, S. Leitch, and R. J. Brodie, "Equity in corporate co-branding: The case of adidas and the All Blacks," European Journal of Marketing, vol. 37, no. 7/8, pp. 10801094, 2003.
[27] A. Fyrberg, "The Olympic Equestrian Games: brand collaboration and associations within a destination and a sports event," International Journal of Sports Marketing and Sponsorship, vol. 9, no. 4, pp. 64-76, 2008.

[28] X. Xing and L. Chalip, "Effects of Hosting a Sport Event on Destination Brand: A Test of Co-branding and Match-up Models," Sport Management Review, vol. 9, no. 1, pp. 49-78, 2006/05/01/ 2006.

[29] J.-N. Kapferer, The New Strategic Brand Management: Advanced Insights and Strategic Thinking. London: Kogan Page, 2012.

[30] R. Priluck Grossman, "Co-branding in advertising: developing effective associations," Journal of Product \& Brand Management, vol. 6, no. 3, pp. 191-201, 1997.

[31] K. E. Voss and B. S. Gammoh, "Building Brands through Brand Alliances: Does a Second Ally Help?," Marketing Letters, journal article vol. 15, no. 2, pp. 147-159, 2004.

[32] K. Waters, "Dual and Extension Branding: Using Research to Guide Design Decisions and Branding Strategy," Design Management Journal (Former Series), vol. 8, no. 1, pp. 26-32, 1997.

[33] R. Venkatesh, V. Mahajan, and E. Muller, "Dynamic co-marketing alliances: When and why do they succeed or fail?," International Journal of Research in Marketing, vol. 17, no. 1, pp. 3-31, 3/31/2000.

[34] R. B. DiPietro, "The Case against Multibranding Strategy," Cornell Hotel and Restaurant Administration Quarterly, vol. 46, no. 1, pp. 96-99, February 1, 20052005.

[35] A. R. Rao and R. W. Ruekert, "Brand alliances as signals of product quality.," Sloan management review, vol. 36, no. $1,1994$.

[36] R. Agnihotri, P. Kothandaraman, R. Kashyap, and R. Singh, "Bringing "social" into sales: The impact of salespeople's social media use on service behaviors and value creation," Journal of Personal Selling \& Sales Management, vol. 32, no. 3, pp. 333-348, 2012.

[37] L. Leuthesser, C. Kohli, and R. Suri, "2+2=5? A framework for using co-branding to leverage a brand," Journal of Brand Management, vol. 11, no. 1, pp. 35-47, 2003// 2003. [38] J. H. Washburn, B. D. Till, and R. Priluck, "Cobranding: brand equity and trial effects," Journal of Consumer Marketing, vol. 17, no. 7, pp. 591-604, 2000.

[39] W. G. Mangold and D. J. Faulds, "Social media: The new hybrid element of the promotion mix," Business Horizons, vol. 52, no. 4, pp. 357-365, 7// 2009.

[40] B. Popp, C. C. Germelmann, and B. Jung, "We love to hate them! Social media-based anti-brand communities in professional football," International Journal of Sports Marketing and Sponsorship, vol. 17, no. 4, pp. 349-367, 2016. [41] J. Howison, A. Wiggins, and K. Crowston, "Validity Issues in the Use of Social Network Analysis with Digital Trace Data," (in English), Journal of the Association for Information Systems, vol. 12, no. 12, pp. 767-797, 2011.

[42] R. K. Yin, Case Study Research: Design and Methods, 3rd ed. Thousand Oaks, CA: Sage Publications, 2003.

[43] J. Gerring, Case study research: principles and practices. Cambridge University Press, 2006.

[44] K. M. Eisenhardt and M. E. Graebner, "Theory building from cases: Opportunities and challenges," (in 
English), Academy of Management Journal, vol. 50, no. 1, pp. 25-32, Feb 2007.

[45] G. Walsham, "Interpretive Case-Studies in Is Research - Nature and Method," (in English), European Journal of Information Systems, vol. 4, no. 2, pp. 74-81, May 1995.

[46] J. Harrison, "RSelenium: R Bindings for Selenium WebDriver. R package version 1.4.0.," ed, 2016.

[47] H. Wickham, "rvest: Easily Harvest (Scrape) Web Pages," ed, 2015.

[48] H. Chen, "VennDiagram: Generate High-Resolution Venn and Euler Plots," R package version 1.6.17. ed, 2016.

[49] J. vom Brocke, S. Debortoli, O. Müller, and N. Reuter, "How In-memory Technology Can Create Business Value: Insights from the Hilti Case," CAIS, vol. 34, p. 7, 2014 [50] F. A. Nielsen, "A new ANEW: Evaluation of a word list for sentiment analysis in microblogs," in Proceedings of the ESWC2011 Workshop on 'Making Sense of Microposts':Big things come in small packages 718 in CEUR Workshop Proceedings, 2011.

[51] M. Jockers, "Syuzhet: Extract Sentiment and Plot Arcs from Text," ed, 2015.

[52] S. M. Mohammad and P. D. Turney, "Emotions evoked by common words and phrases: Using Mechanical Turk to create an emotion lexicon.," in Proceedings of the NAACL HLT 2010 workshop on computational approaches to analysis and generation of emotion in text, 2010, pp. 26-34: Association for Computational Linguistics.

[53] D. Derks, A. E. R. Bos, and J. v. Grumbkow, "Emoticons and social interaction on the Internet: the importance of social context," Computers in Human Behavior, vol. 23, no. 1, pp. 842-849, 1// 2007.

[54] J. Peterka-Bonetta, "Emoticons decoder for social media sentiment analysis in R," ed, 2015.

[55] R. W. Jensen, Y. B. Limbu, and Y. Spong, "Visual Analytics of Twitter Conversations about Corporate Sponsors of FC Barcelona and Juventus at the 2015 UEFA Final," International Journal of Sports Marketing and Sponsorship, vol. 16, no. 4, pp. 3-9, 2015.

[56] M. Jockers, Macroanalysis: Digital Methods and Literary History. University of Illinois Press, 2013.

\section{Appendix A}

Table A: Emotional Tone Welch Two Sample t-test

\begin{tabular}{|lllll|}
\hline \multirow{2}{*}{$\begin{array}{c}\text { Emotional } \\
\text { tone }\end{array}$} & $\mathbf{t}$ & df & \multicolumn{2}{c|}{ Means } \\
\cline { 3 - 5 } & & & Zlatan & $\begin{array}{c}\text { Man } \\
\text { United }\end{array}$ \\
\hline Anger & $7.94 *$ & 33637 & 0.040 & 0.027 \\
\hline Anticipation & $5.60^{*}$ & 32605 & 0.120 & 0.102 \\
\hline Disgust & $10.97 *$ & 36123 & 0.049 & 0.030 \\
\hline Fear & $8.19^{*}$ & 33458 & 0.042 & 0.028 \\
\hline Joy & $5.93^{*}$ & 32952 & 0.109 & 0.091 \\
\hline Sadness & $6.94 *$ & 33170 & 0.035 & 0.024 \\
\hline Surprise & $8.00^{*}$ & 35897 & 0.069 & 0.050 \\
\hline Trust & $6.89 *$ & 30881 & 0.153 & 0.129 \\
\hline Negative & $11.84 *$ & 35370 & 0.083 & 0.055 \\
\hline Positive & $11.69 *$ & 33245 & 0.232 & 0.178 \\
\hline *p-values $<0.001$ & & & \\
\hline
\end{tabular}

[57] H. Wickham, ggplot2: Elegant Graphics for Data Analysis. New York: Springer-Verlag 2009.

[58] I. Fellows, "wordcloud: Word Clouds," ed, 2014.

[59] M. Ozanian. (2017) The World's Most Valuable

Soccer Teams 2017. Forbes. Available:

https://www.forbes.com/sites/mikeozanian/2017/06/06/the-

worlds-most-valuable-soccer-teams-2017/\#41c7ab8c77ea

[60] BBC, "Zlatan Ibrahimovic joins Paris St-Germain from AC Milan," in $B B C$, ed, 2012.

[61] J. Gaughan, "Zlatan Ibrahimovic announces Manchester United transfer on Instagram as Swedish superstar says: 'I am coming'," in Mail Online, ed, 2016.

[62] K. S. Cameron and R. E. Quinn, Diagnosing and changing organizational culture: Based on the competing values framework. John Wiley \& Sons, 2005.

[63] L. Grabowski, C. Neher, T. Crim, and L. Mathiassen, "Competing Values Framework Application to Organizational Effectiveness in Voluntary Organizations: A Case Study," (in English), Nonprofit and Voluntary Sector Quarterly, vol. 44, no. 5, pp. 908-923, Oct 2015.

[64] A. M. Kaplan and M. Haenlein, "Users of the world, unite! The challenges and opportunities of Social Media," Business Horizons, vol. 53, no. 1, pp. 59-68, 1// 2010.

[65] D. Nylén, J. Holmström, and K. Lyytinen, "Oscillating Between Four Orders of Design: The Case of Digital Magazines," Design Issues, vol. 30, no. 3, pp. 53-68, 2014.

[66] B. Boad, "The Risks and Pitfalls of Co-Branding," in Co-Branding: The Science of Alliance, T. Blackett and B. Boad, Eds. London: Palgrave Macmillan UK, 1999, pp. 38-46.

[67] M. Jockers, Text analysis with $R$ for students of literature. New York: Springer, 2014.

[68] R. Socher, Perelygin, A., Wu, J. Y., Chuang, J., Manning, C. D., Ng, A. Y., \& Potts, C. , "Recursive deep models for semantic compositionality over a sentiment treebank," in Proceedings of the conference on empirical methods in natural language processing (EMNLP), 2013, vol. 1631. 